\title{
The automated system for bandsaw blade properties measurement
}

\author{
Tomas Sysala ${ }^{1, *}$, Karel Stuchlík ${ }^{1}$, and Petr Neumann ${ }^{2}$ \\ ${ }^{1}$ TBU in Zlin, Dept. of Automation and Control Engineering, Faculty of Appl. Informatics, Nad Stranemi 4511, Zlin, Czech Rep. \\ ${ }^{2} \mathrm{TBU}$ in Zlin, Dept. of Electronics and Measurements, Faculty of Applied Informatics, Nad Stranemi 4511, Zlin, Czech Republic
}

\begin{abstract}
The article describes the bandsaw blade properties innovative method design and realization. The introduction contens individual bandsaw parts description, including their important parameters overview. The innovative methods design delineation follows. The constructed device based on our design minimizes the human error influence. Moreover, it is collecting and archiving measured data. The article covers also the design and software realization. In the end, some measured data examples are stated.
\end{abstract}

\section{Introduction}

Wood is one of oldest materials exploited in human activities. In spite of fact that it has been replaced in many areas with plastic materials, with iron and with concrete, it it is still a favourite material because of its specific characteristic.

Various saw types serve for wood priming and shaping. For small wooden parts, there uses either handsaw or motor saw types. Larger wooden parts are processed with special more powerful saw designs. The bandsaws represent a big group of processing tools.

The bandsaw consist of two big wheels called upper wheel and lower wheel. The bandsaw blade is tighten over both wheels.

Both wheels must have a convex circumference shape from a certain bandsaw blade width. It facilitates the blade to keep the right position safely. That solved the preceeding project. $[10,11]$

The high production quality and preventive maintenance requirements place on the bandsaw blade.

The project goal was to realize an equipment replacing the man for sake of quality assessment and the grade of wear objectively. The data automatic archiving possibility is also highly preferable for a reliable functioning. The archived data serve for a time dependent comparison, wear out analysis and other blade parameters change.

This project is a result of cooperation with Dudr Tools Ltd. Company. That company is oriented on the saw baldes production and servicing.

\section{Bandsaws}

Bandsaws are belonging to woodworking tools. Those tools are employed for example in sawmills for tree trunk cutting in lumber like flitches, logs, planks or slabs. [1,2]
The bandsaw cutting tool is an endless saw band tighten typically between two wheels. Both saw band ends are welded together. The tighten saw blade is running at a constant speed relevant to the type of material to be cut. [4]

The bandsaw can be classified according to various criteria, like for instance the orientation of bandsaw blade (vertical, horizontal), stationary or portable, multiblade design, etc.

The universal joiner's bandsaws rank among the most extensively used bandsaws. The other very frequently used bandsaws are log bandsaw, squaring bandsaw and dimension bandsaw types.

Except for case apart, all bandsaws are in fixed or immobile verions. [1]

In comparison with other saw types, the bandsaw has thanks to thin blade the smallest cutting loss so that it produces only a few amount of sawdust. The cutting surface is smooth and high quality. The bandsaw enables also the corner cutting. Unlike the other saws, the noise level is remarkably lower.

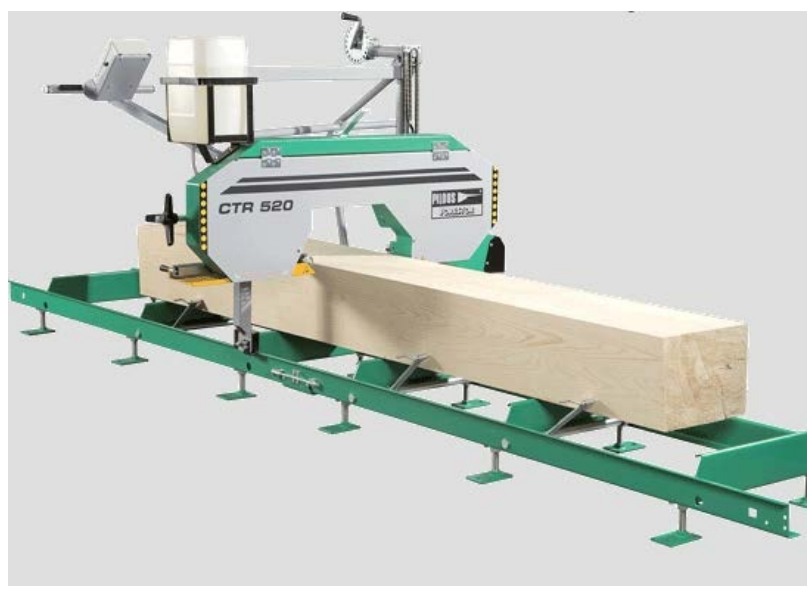

Fig.1. A bandsaw example. [2]

\footnotetext{
*Corresponding author: sysala@utb.cz
} 


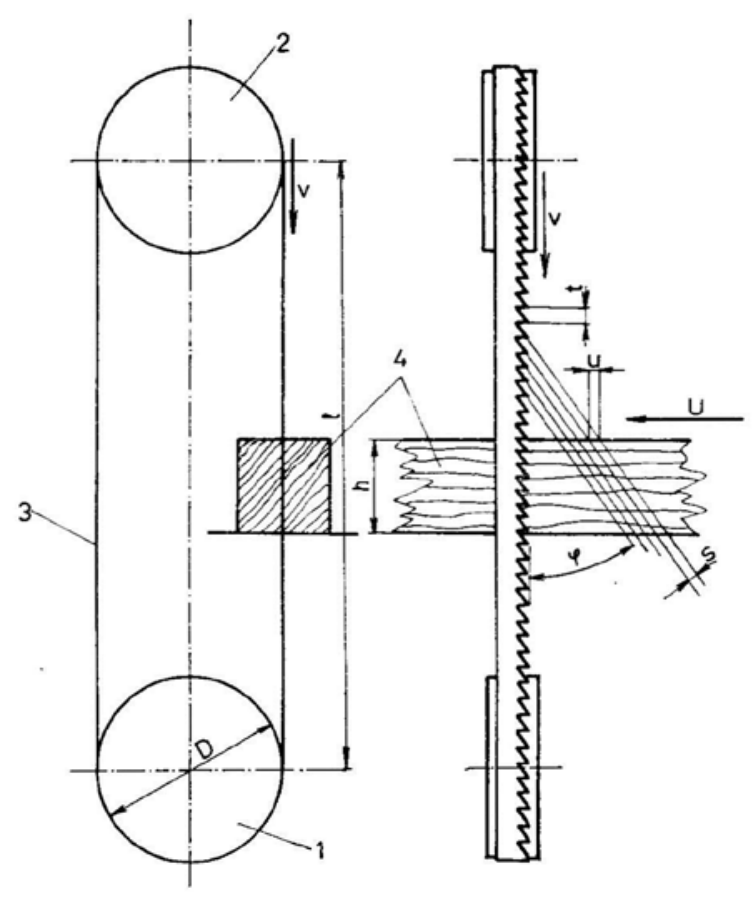

Fig. 2. The bandsaw cutting principle. [1]

\subsection{The bandsaw method of operation}

The bandsaw function is based on band blade (3) that is tighten between two wheels, both the driving one (1) and the driven one (2). In an active state, the band blade runs with a constant velocity. The processed material (4) is fed either manually or mechanically.

\subsubsection{Log bandsaw}

The log bandsaws find application in sawmills for sawlogs processing.

They exist in two variants - both horizontal and vertical. They consist most frequently from following components: equipment, clamping carriage, roll-in and revolving tool, cylinder conveyor, controller unit.

Equipment consists of a base, a stand, two wheels bandsaw blade and of a driving unit.

\subsection{Band saw wheel}

The bandsaw wheels mentioned above, both the driving one and the driven one belong to bandsaw basic components. The driving wheel ensures the cutting assembly movement, and the driven wheel ensures a proper tightening and saw blade guidance.

The wheels contact area (crown) where band blade sits has a convex shape contour for saw belt width roughly above $70 \mathrm{~mm}$ for both dimension and log bandsaws. The crown exerts a pulling force, moving the blade to the top of the wheel.

The typical wheel contact area (crown) contours illustrates Fig. 3.

The wheels wear down in course of time what causes that the saw blade doe not sit in place like expected. The wheel starts cracking, and tend not to keep the cut line during sawing. There is necessary to refurbish the blade contact area to the original shape. $[3,4]$

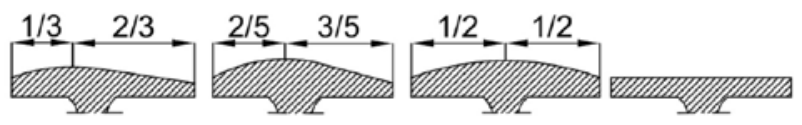

Fig. 3. Band saw wheels convex crosssection contours. [4]

\section{4 The trunk saw blade characteristic}

The length of bandsaw blade derives from the wheels diameter and from the distance of their axe. The blade thickness depends on the wheels diameter. The blade thickness must not exceed the one thousand's of wheel diameter minus $0.1 \mathrm{~mm}$. If the blade thickness is higher, the saw blade stresses excessively. $[1,4]$

The saw teeth shape and arrangement origins from a few basic shapes according to the following picture:
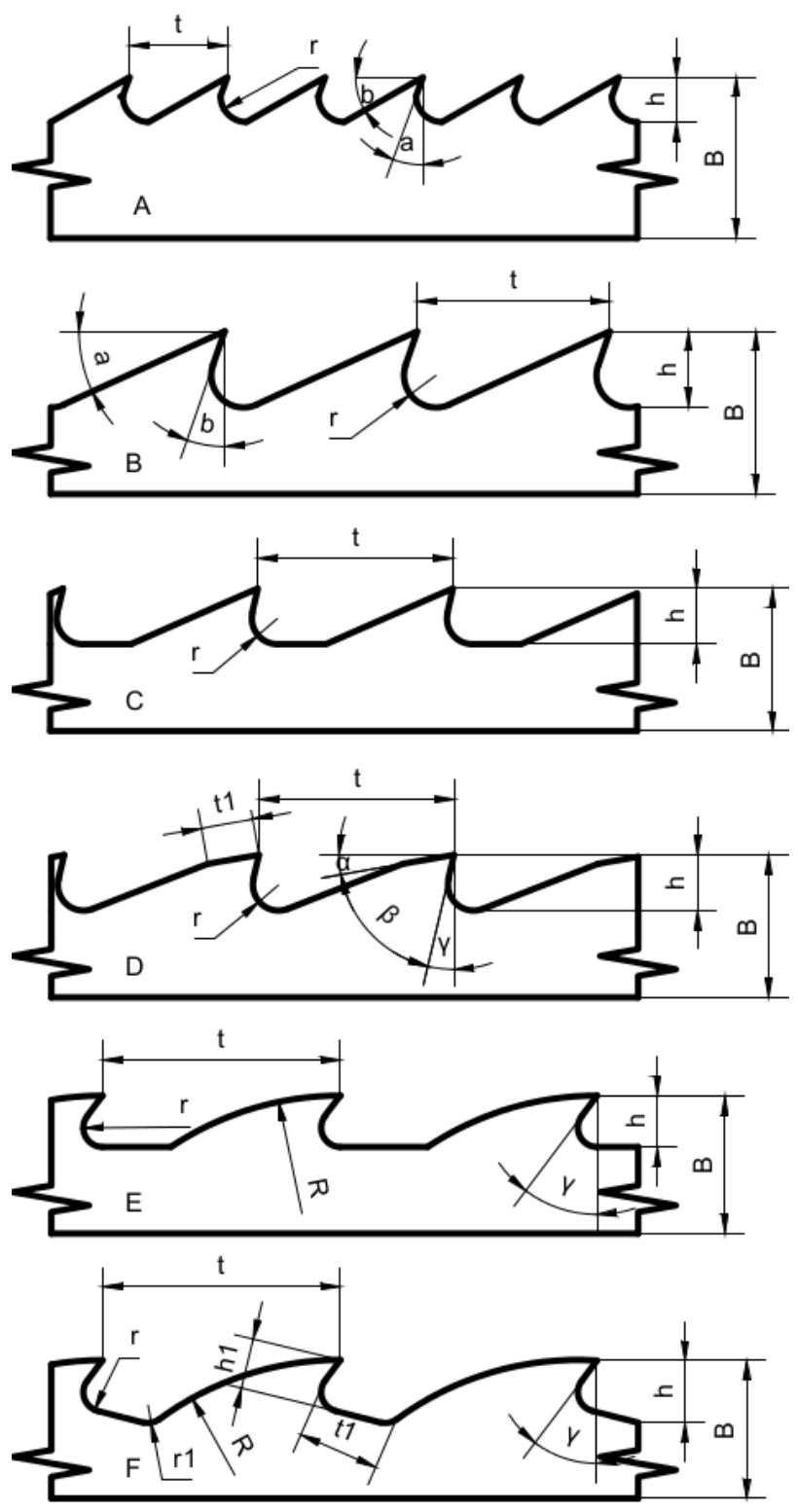

Fig. 4. The basic saw teeth shapes example. [4] 
The trunk saw blades correspond with variants B to F.

The parameters are as follows:

$\mathrm{t} \quad-$ the tooth pitch [mm],

t1 - tooth flank length [mm],

$\mathrm{h}-$ Gullet depth [mm],

$\mathrm{r} \quad$ - the radius of gullet [mm],

$\mathrm{R}-$ the radius of tooth flank [mm],

B - Blade width [mm]. [4]

\subsection{The trunk saw blade manufacturing}

The saw blade material is a high quality tool steel thermally processed for a required hardness. That steel is enriched with some elements like chromium, nickel, manganese and others. The steel material supplies in a band form or in coils. The manufacturing consiste from following procedures:

- saw band straightening and teeth cutting,

- saw band rolling to release tension,

- saw band teeth forming,

- sharpening.

\section{Saw band inspection}

The saw band manufacturing is a demanding process which final quality highly influence both the human failure and the correct functionality of individual stages in process, like grinding, rolling and other.

The thoroughgoing inspection checks whether the saw band has corresponding characteristic.

\subsection{Actual saw blade inspection methods}

The Dudr Tools comp. has commissioned the shift foreman to perform the saw blade inspection so far. Foreman is responsible for a proper inspection, and in the case of acceptance, he transfers the saw band to dispatch office.

The inspection bench is a special fixture for saw bend testing. The tested parameters are as follows:

- Blade back - it is the width of saw band except for the teeth part. The blade back width measures along the band in two or three positions. All readings should be the same.

- Straightness - it is a deviation specified in millimeters and defined as lateral deviation of the edge from a straight line. Putting the ruler to the blade back edge should not indicate any irregularity. The edge line must be absolutely straight.

- Crowning - Putting the hair ruler across the blade width should indicate the light slit. The preferred ruler positions are the weld seam, and three to four positions along the saw blade band.

- Tooth quality - test checks for instance stelliting result. Tips must be sharp. The other parameter to be checked is the teeth width tolerance which is limited to $\pm 0,05$ $\mathrm{mm}$. The tooth side shape should regular and straight, not a "banana" deformation. The tooth face must be in line.

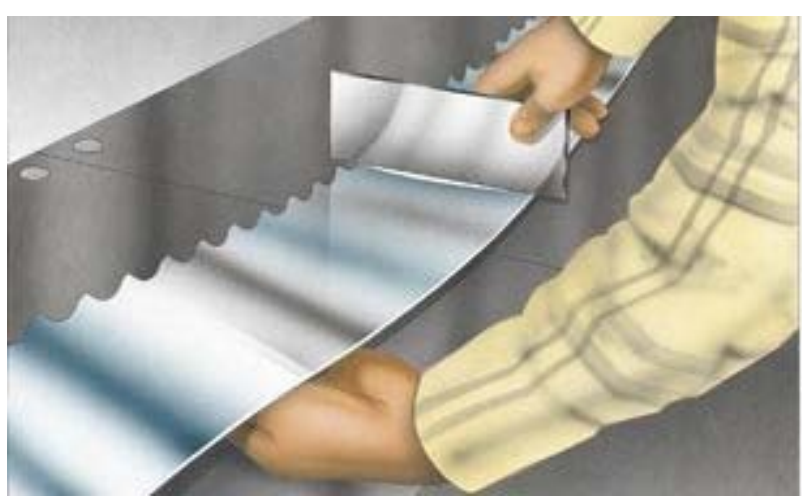

Fig. 5. The saw blade crowning inspection. [14]

\subsection{Actual inspection methods drawbacks}

There are a few drawbacks in the current bandsaw blade inspection procedure.

The first drawback is human error. Every worker even the best knowledgeable and experienced performes the inspection differently. The inadvertence in relation to the high quantity of teeth is expectable keeping in mind that trunk bandsaw blades have commonly more that 100 of it. It is impossible to catch sight of tiny deviation from specifications at every tooth from such amount teeth during visual inspection. Furthermore, it is difficult to set a corresponding criterion for a subjective decision what is acceptable and what already not. The problem can appear only at the customer in course of sawing process.

Further problem consists in the absence of detail inspection records nowadays. Operator just checks whether the bandsaw blade complies with expectation or not. The detail characteristic data set simply does not exist for any particular bandsaw blade passed on distribution department.

\subsection{Automatic saw blade inspection design}

The bandsaw blade inspection asks for automation. The model arrangement represents a fixture where the blade is temporarily installed and initially set. The blade is driven with an electric motor like in a real mode. Running through the fixture, the blade passes various sensors which are reading its parameters. All that runs without operator's intervention. That fixture system measures the blade length and the teeth count. The blade back deviations are measured as well. The strightness is measured at the straight parts of running blade, the curved part, the required tensile crowning is measured. The machine vision system checks individual tooth. The whole inspection process is recorded as the report and saved into a database.

\section{Automated inspection}

The following text refer to our newly designed inspection equipment as inspection bench. The Dudr Tools experts have designed the mechanical part of inspection bench. 
The figure below presents the current inspection bench model afterbsome modifications with the bandsaw blade installed.

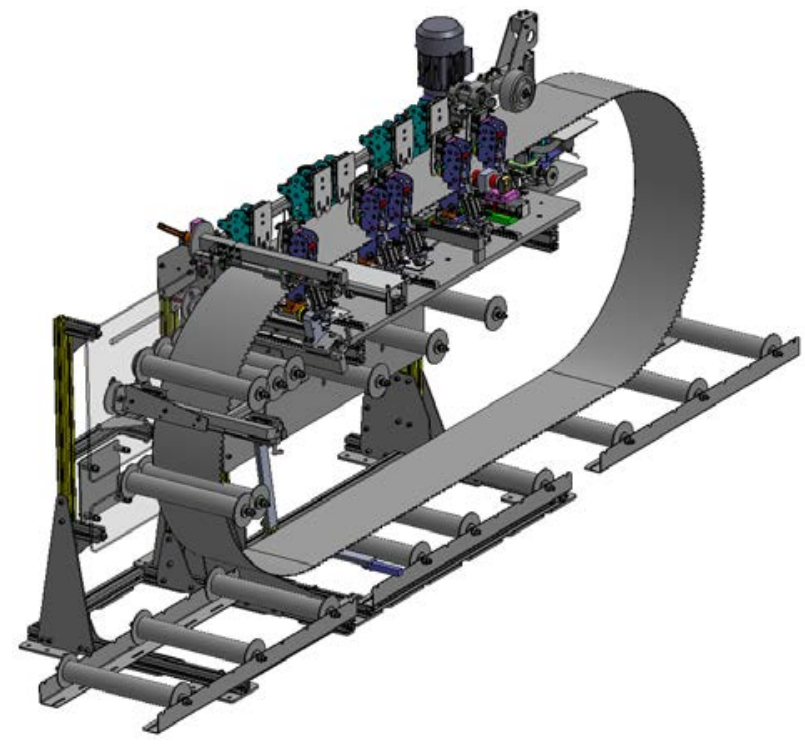

Fig. 6. The inspection bench design model. [9]

The inspection bench can inspect bandsaw blades of both various length and width.

The following picture presents the bloc diagram of our inspection system. A PLC module controls all actors, and it collects data from sensors. Data is transferred to a personal computer that serves as displaying unit, and it is processing the video camera signal. The camera is connected via USB port. There is an imaging start/stop trigger switch connected to camera. Data is evaluated, and results are sent to the superwising system in the company LAN. The PLC control HMI panel and the illuminating unit for the machine vision are also included. [9]

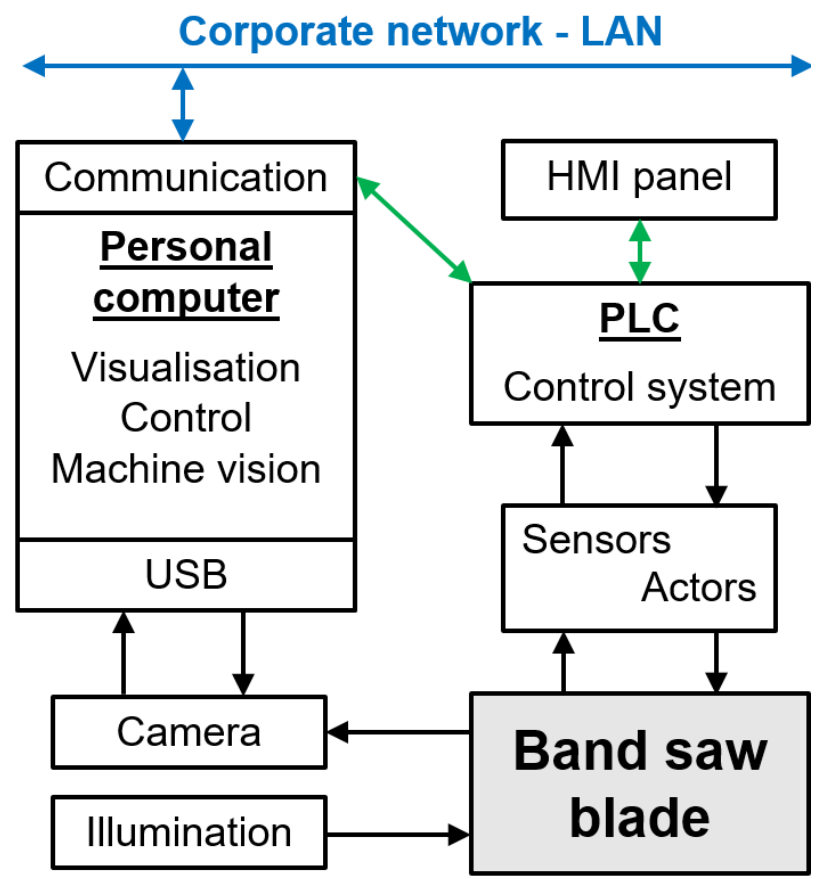

Fig. 7. The block diagram of our system.

\section{The system elements description}

\section{1 Control unit}

The PLC module Simatic S7-1200 by Siemen controls all drives and sensor signal processing. That PLC module has integrated I/Os, Profinet interface serving also for PLC programming and for the HMI interconnection.

PLC Simatic modules are programmed by the TIA (Totally Integrated Automation) tool which serves also for HMI panels programming.

\subsection{Data processing, visualization, machine vision}

Control Web application ensures data processing and visualization.

That application together with a corresponding driver supports reliable communication with PLC Simatic module, with the dtabase, and it supports namely the VisionLab machine vision system.

\subsection{Sensors}

Following sensors are ensuring the bench basic functionality:

- blade feed sensing,

- length measurement,

- teeth counting,

- blade straightness measurement,

- crowning measurement,

- blade back measurement,

- tooth set measurement.

In relation to the control system, all sensors are in PNP circuitry design and DC power supply of 24 volts.

\subsubsection{Length measurement}

Bandsaw blade length is measured by the incremental rotational sensor Larm IRC 310/2500 PB. It is fixed via a clutch to the driving rubber roll.

\subsubsection{Blade origin sensor}

The optoelectronic sensor, model LR-W70C by Keyence, senses the origin of the blade. That sensor can be programmed for an arbitrary colour detection with a required tolerance. It simply means that a hand made colour mark with felt tip pen refers to the blade origin. The sensor reads the first mark pass in sensor field of view as origin, and the second pass reads as the end of blade.

\subsubsection{Teeth counting}

The further important parameter of bandsaw blade is the total count of teeth.

There is a binary sensor fixed at a suitable position of inspection bench frame. The position should make 
possible the detection of gaps between teeth during the blade run. The consecutive registration of output signal's either leading or trailing edge gives in sum the final cout of teeth along the whole length of blade.

A one-way optical light gate applies as the counting sensor.

\subsubsection{Saw back measurement}

The inductive sensor with analog output, model DW-AS-509-M12-390 by Contrinex ensures the saw back measurement (the toothless blade edge). Its sensing distance is in the rnge from 0 to $6 \mathrm{~mm}$ what corresponds with the output voltage in the ranege 0 to 10 volts. The sensor's tube-shaped body has M12 thread. [16]

\subsubsection{Flatness measurement}

The blade flatness measurement, or also the profile measurement, requires the sensor positioned in a section where the inspected blade is mostly flat.

The sensor DW-AS-509-M12-390 by Contrinex makes the required service also here. It is again connected to an analog onput of PLC (0 to 10 volts DC).

\subsubsection{Crowning measurement}

The blade crowning (convexity) measurement uses the same principle like planarity measurement.

Crowning The distinct crowning measurement succeeds best where the blade bends. In our case, the sensor is positionned on the swing-out arm in the front part of bench. [Fig. 6]

The blade crowning measures with the triangulation sensor, model OD2-N50W10A0 by SICK. [7]

\subsubsection{Machine vision system}

Machine vision system represents the last necessary module including ligting, lens and camera.

There was necessary to look for a camera compatible with the chosen system VisionLab with the Control Web application.

At the same time, camera needs to have an external trigger option. Only cameras of DataCam family by Moravské Přístroje offer that characteristic. Those DataCam cameras have high sensitive CCD sensors, very low picture noise, a firm aluminium body, wide choice of lenses, and USB 2.0 interface for data transfer and power supply.

The Model DataCam DC-2008 with 8 bit ADC fits best in our design.

Camera connects to a PC with Control Web/VisionLab application via USB 2.0 port.

\section{SCADA system}

Interface between the inspection bench and operator creates the SCADA/HMI of Control Web.

\subsection{Control Web}

Control Web is a programming tool for the development and realisation of both visual and control applications. It acts also as a tool for data collection, evaluation and storing. The DataLab IO as well as Control Web are join-stock company Moravské př́stroje products. This company founded in 1991 aims at the development and support of advanced products in the field of electronics and relevant software.

Work in the Control Web programming environment bases on an active exploitation of also called "active devices". These active devices are pre-programmed devices fulfilling particular functions as for instance:

- Devices for user environment creation,

- Control elements,

- Measurement data displaying.

This software communicates with DataLab IO system supporting the magnetic sensor incremental pulse counter very well.

\section{Measurement progress}

There is necessary to calibrate the whole system before starting the inspection process. The PLC program modules for calibration are taking care for that. The communication with PLC goes via HMI panel.

After a successful calibration, we see the actual indicative values at corresponding sensing modules

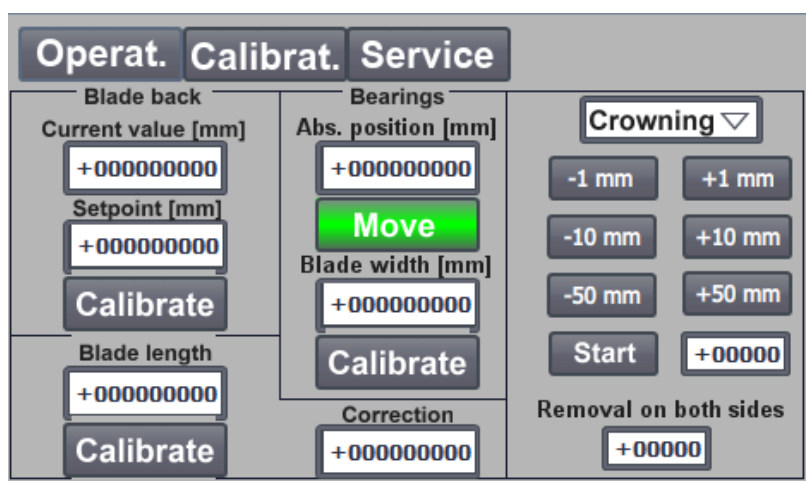

Fig. 8. HMI panel screen example.

The first step is starting point mark on bandsaw blade to inspect somewhere in front of blade start sensor. The next step is "Teeth, Length" button click. The saw blade feed drive switches on. The teeth count performs along tho whole blade length together with the blade length. The actual crowning value, blade back flatness and edge strightness are registered every $10 \mathrm{~mm}$. The machine vision system scans individual tooth quality.

After finalizing the first inspection stage, the blade feed drive stops. The button "across" push activates the second stage of inspection. The blade crowning and flatness across the blade width are measured in five position during blade feed stops.

The corresponding stop positions are determined in relation to the total count of teeth recorded during the first inspection stage. 


\subsection{System output examples}

The data from the particular measurement report can be stored in a database for later use.

The folowing figures illustrate the crowning and the flatness measurement direction in width direction at five positions along the blade length.

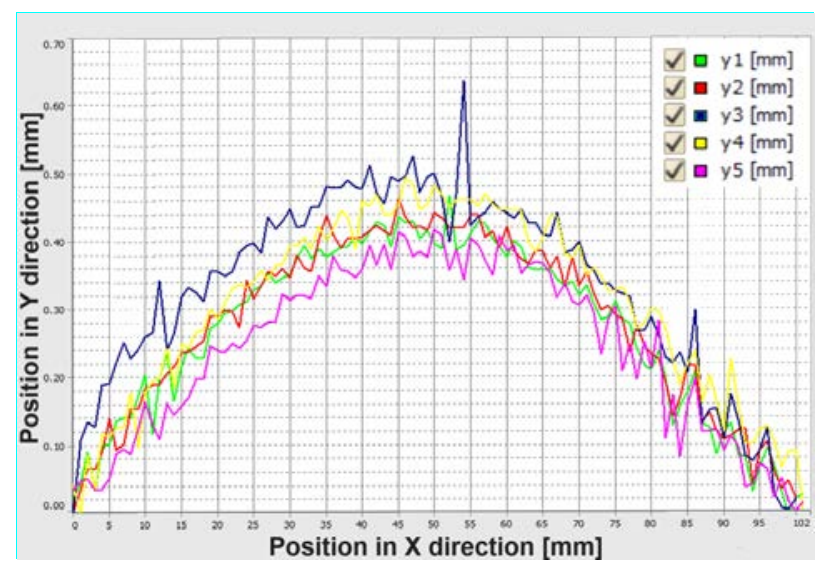

Fig. 9. The crowning shape across the blade width. [9]

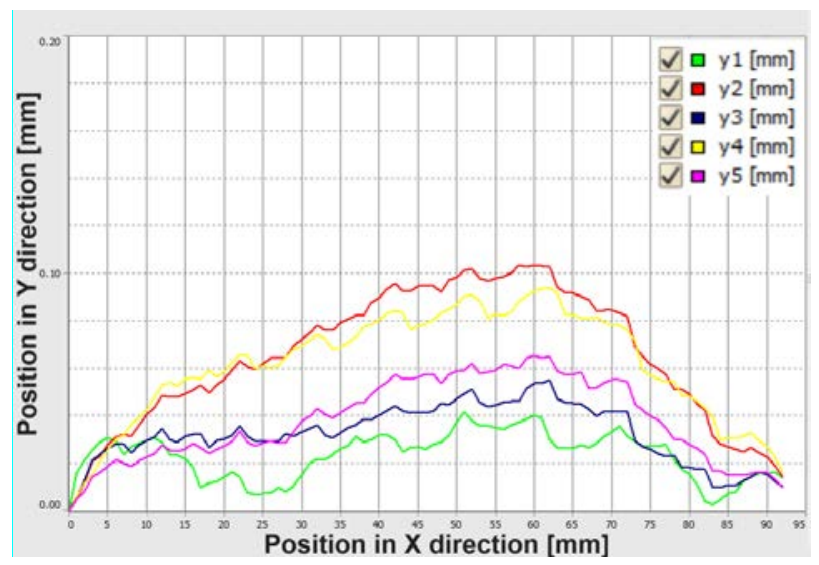

Fig. 10. The flatness course across the blade width. [9]

Graphs show satisfactory results. We can see that crowning shape is regular but a higher deviation in thord measurement. The peak occurs in the middle of blade length, and its heght is about $0,45 \mathrm{~mm}$. The other crowning values are roughly same. The flatness deviation is up to $0.1 \mathrm{~mm}$ what is also a satisfactory result. [9]

\section{Conclusion}

The data archiving posisibility represents the most important contribution of bandsaw blade automatic inspection system designed in our project. It is also a remarkable contribution to the traceability of produced bandsaw blades before dispatching them to customers.

The human error influence on measurement result is minimal. Any operator shloud become same results.

We can expect a high return on investments in the form of bandsaw blades quality increase and customer satisfaction.
This work was supported by the Ministry of Education, Youth and Sports of the Czech Republic within the National Sustainability Programme project No. LO1303 (MSMT-7778/2014) and by the European Regional Development Fund under the project CElPeb No. CZ.1.05/2.1.00/03.0089.

\section{References}

1. L. Maňas, F. Kočara. Stroje a zařizení pro dřevařský prumysl - Machines and equipment for the wood industry - (in czech), 1, 272, (1979)

2. Pilous CTR 520. [Online] Available: http://www.pasove-pily.eu/html/pilous-ctr-520nova-kmenova-pasova-pila-na-drevo-27.html

3. K. Stuchlík, Měrení profilu pásovnice u pásových pil pro pořez kulatiny - (in czech), bachelor work, $\mathbf{1}$, TBU in Zlin, (2015)

4. Š. Barcík, M. Kvietkova, J. Bomba, M. Siklienka, Drevoobráběci nástroje - údržba a provozování (in czech), ISBN 978-80-87415-80-1, 1, (2013)

5. Jirka a spol [Online] Available: http://www.jirkaspol.cz/magneticke-snimace-1.html

6. Sick: Sensor Intelligence [Online] Available: https://www.sick.com/cz/cs/c/PRODUCT_ROOT\#g 132151, (2019)

7. Sick: Sensor Intelligence, [Online] Available: https://www.sick.com/de/en/distance-sensors/shortrange-distance-sensors-displacement/od-value/od2n50w10a 0/p/p185870, (2019)

8. Moravian Instruments, [Online] Available: https://www.mii.cz/cat?id=189\&lang=409, 2019

9. K. Stuchlík, Měření pilových pásů - (in czech), master's thesis, 1, TBU in Zlin, (2017)

10. T. Sysala, K. Stuchlík, P. Neumann, Matec Web of Conferences, ISSN 2261-236X, 210, (2018)

11. T. Sysala, K. Stuchlík, P. Neumann, WSEAS Transactions on Systems and Control, ISSN/E-ISSN 1991-8763 / 2224-2856, 13, (2018)

12. Pilana, [Online] Available: http://www.pilana.cz/ ?download=cz/pilana-kmenove-pilove-pasy-cz.pdf

13. Dudr Tools, [Online] Available: http://www.dudr.cz/www/docs/kat_dudr_kmenove pasy_fin_CZ_2_web.pdf, (2019)

14. BÖHLER-UDDEHOLM PRECISION STRIP AB. Wood Bandsaw Steel, [Online] Available: https://www.uddeholm.co.uk/english/files/Wood_Ba ndsaw_Steel.pdf, (2019)

15. VSE180-2P42432: Optoelektronické snímače. SICK Česko, [Online] Available: https://www.sick.com/cz/cs/optoelektronickesnimace/optoelektronicke-snimace/v180-2/vse1802p42432/p/p226942, (2019)

16. Contrinex Analog Output Inductive Sensors. Clearwater Technologies Inc., [Online] Available: http://www.clrwtr.com/PDF/CONTRINEX/CONTR INEX-Analog-Series-Prox-Sensors.pdf, (2019) 